\title{
POSTMORTEM STUDY ON INDIGESTIBLE FOREIGN BODIES IN RUMEN AND RETICULUM OF CATTLE (CASE: HARAMAYA AND AWADAY MUNICIPAL ABATTOIRS, EASTERN ETHIOPIA)
}

\author{
Ibsa AMIN and Tewodros FENTAHUN ${ }^{\star 凶}$ \\ Unit of Biomedical Sciences, College of Veterinary Medicine and Animal Sciences, University of Gondar, P.O. Box 196, Gondar, Ethiopia. \\ Email: tedyvet@gmail.com; 0.:2955-5638 \\ Supporting Information
}

\begin{abstract}
A cross-sectional study was conducted from November, 2017 to March, 2018 at Haramaya and Awaday Municipal Abattoirs of Oromia Regional State, Eastern Ethiopia, with the objectives of assessing the prevalence of rumen and reticulum foreign bodies, identifying types of foreign bodies and associated risk factors for the occurrences of foreign bodies. Following appropriate ante-mortum examinations, postmortem examinations were employed for the recovery of foreign body from rumen and reticulum. The study animals were selected by using systematic random sampling using regular interval to study animal from the total slaughtered animals. From a total of 384 (207 female and 177 male) cattle examined, 41.7\% ( $n=160)$ were found to contain foreign bodies at slaughter. When the prevalence was compared between genders, breed, among different age groups, and different body condition score, higher prevalence of foreign bodies $50.7 \%$, $\mathbf{7 5 . 0} \%, \mathbf{8 0 . 0} \%, \mathbf{8 3 . 3} \%$, were observed in female, cross breed, age older than 10 years, and animal having poor body condition score respectively. These aforementioned factors are considered as potential risk factors were highly significantly associated with the occurrence of foreign bodies. Rumen harbored mostly plastic materials while reticulum was the major site for the retention of metallic objects. The non-penetrating foreign bodies have higher prevalence than penetrating foreign bodies. The commonly recovered non-penetrating foreign bodies were plastics $(46.9 \%)$, cloth $(30.0 \%)$, rope $(21.3 \%)$ and leather $(18.8 \%)$. The penetrating foreign bodies were metals (5\%). Plastics were recovered as the most common foreign bodies and followed by cloths, Ropes, and leathers. It is concluded that the detection of this level of prevalence of foreign bodies in cattle causes high mortality and morbidity, reduced production and productivity. Therefore, appropriate solid waste disposal system need to implement in the study area to prevent health risk of ruminants and also to protect the environment.
\end{abstract}

Keywords: Body Condition Score, Cattle, Foreign body, Reticulum, Rumen.

\section{INTRODUCTION}

Ingestion of foreign bodies is one of the major bottle necks to livestock development in the tropics (Gupta and Single, 2013; Fasil, 2016). In Ethiopia, ruminants are kept under an extensive type of management are likely to be exposed to the ingestion of indigestible garbage from various sources due to a wide spread environmental contamination with plastic bags, absence of policy to protect environment and frequent occurrence of drought that predispose animals to nutritional deficiency and pica (Abebe and Nuru, 2011).

Gastrointestinal foreign bodies are among the most common surgical emergency in veterinary medicine. Cattle are more susceptible to foreign body syndrome than small ruminants because cattle do not use their lips for prehension, they are more likely to ingest foreign bodies than small ruminants as they are more likely to eat chopped feed in which foreign bodies may be incorporated (Bayne and Edmondson, 2020).

According to different studies, the common non-piercing foreign bodies commonly ingested by ruminants are plastic bags, sack thread, ropes, leather, rubber, bed linen, pieces of lead pipe, straw baskets, hair and plant fibers (bezoars) (Anwar et al., 2013). While wire, needles, nails and stones are the major penetrating foreign bodies isolated from ruminants (Bwatota et al., 2018). The indiscriminate feeding habits and mineral deficiency make them susceptible to inadvertent ingestion of foreign materials (Priyanka and Dey, 2018).

Environmental pollution is one of the growing problems for grazing animals due to absence of recycling industries, cleaning of environment cultures, improper disposal of plastic bags; free grazing animals eat plastic bags especially in towns and villages (Bhaskara and Sasikala, 2012; Reuters, 2019). These plastic bags are indigestible and their accumulation in the rumen of grazing animals may lead to adverse effect on health (Ghurashi et al., 2009); plastic bags resist to biodegradation and pollute for decades and centuries and pose great risk to human health and environment (Ramaswamy and Sharama, 2011). Feed shortage usually occurs at specific time of the year in most part of Ethiopia. Moreover, most owners do not provide supplementary feed to animals. These in turn may predispose the animals to negative energy balance and force them to feed on unusual materials including plastics, clothes, ropes and even metallic substances (Bhaskara and Sasikala, 2012; Tesfaye et al., 2012). In addition, industrialization and mechanization of agriculture have further increased the incidence of foreign bodies in the animals (Semieka, 2010). The ingestion of foreign bodies causes various problems in different organ of the animal mainly in rumen and reticulum. The problem that are caused vary with the duration that the foreign body 
has been present, the location of foreign body, the degree of obstruction that is caused as well as problems associated with the material of the foreign body. Glossitis, esophagitis, ruminitis, impaction of rumen, traumatic pericarditis (TP) and traumatic reticulo peritonitis (TRP) are the possible health problems which can be caused by the ingestion of foreign bodies by the cattle (Desiye and Mersha, 2012). Traumatic reticulo-peritonitis disease in cattle is caused by the ingestion of foreign bodies in the reticulum swallowed metallic objects such as nail or pieces of wire fall directly on the reticulum or pass into the rumen and subsequently carried over the rumeno-reticular folds into the cranioventral part of the reticulum (Radostits et al., 2007; Braun et al., 2018).

The presence of foreign bodies in the rumen and reticulum hampers the absorption of volatile fatty acids and consequently reduction in the rate of animal fattening (Bassa and Tesfaye, 2017) the perforation of the wall of the reticulum can also allow leakage of ingest and bacteria which contaminates the peritoneal cavity, resulting in local or diffuse peritonitis (Anwar et al., 2013).

Animals with large amount of blunt foreign bodies show anorexia, depression, intermittent respiratory distress, recurrent rumen tympany, rumen stasis, dehydration, reduced milk yield, distended left paralumbarfossa and sometimes vomiting (Reddy and Sasikala, 2012; Abu-Seida and Al-Abbadi, 2014). Tachycardia, muffled heart sounds, distended jugular veins, pericardial sounds like splashing, rubbing or squeaking sounds, brisket and ventral edema were observed in cattle with traumatic reticulopericarditis (Ramin et al., 2011). Shrunken rumen, strangulated foreign bodies, congested ruminal mucosa and ulceration are the common necropsy findings in animals with foreign body syndrome (Abu-Seida and Al-Abbadi, 2016; Serem et al., 2019).

This disease is of high economic importance and serious due to severe reduction in milk and meat production, treatment costs, potential fatalities and fetal losses in affected animals (Sileshi et al., 2013). The condition is usually common in urban and peri- urban areas where extensive building are carried out and proper plastic material disposal is not conditioned and so thrown on roads and near the fence or anywhere and that is way our dairy cattle are dying mainly associated with foreign bodies (Ramaswamy and Sharama, 2011). Many efforts were made to study infectious disease prevalent in the country, however, solid environmental pollution (Foreign Body's) have been given lesser attention to be treated as a separate health problem. Therefore, the objectives of current study were to assess the prevalence of rumen and reticulum foreign bodies in cattle slaughtered at Haramaya and Awaday Municipal Abattoirs. As well as, the type of rumen and reticulum foreign bodies will be identified.

\section{MATERIALS AND METHODS}

\section{Study area}

The study was conducted in Haramaya and Awaday municipal abattoirs, Eastern Hararghe zone, and Oromia region. The Awaday town is located 9021'10" N, 42013'46" E with average altitude of 1962 m at a distance of 510 $\mathrm{km}$ from capital Addis Ababa (Mekonnen and Uttama, 2014).The Haramaya town is located at $509 \mathrm{Km}$ from Addis Ababa at an elevation of 1400 to 2340 meter above sea level. The town situated between a latitude and longitude of $42^{\circ} 01^{\prime} \mathrm{E}$ and $9^{\circ} 24^{\prime} \mathrm{N}$ respectively. The mean annual rainfall received range from 600 to $1260 \mathrm{~mm}$ with bimodal nature Minimum and maximum annual temperature range from $6^{\circ} \mathrm{C}$ to $12^{\circ} \mathrm{C}$ and $17^{\circ} \mathrm{C}$ to $25^{\circ} \mathrm{C}$ respectively. The relative humidity varies between $60 \%$ to $80 \%$. The farming system in the area is mixed type (crop-livestock production). The total population of people in the area is estimated to be 352,031 according to (CSA, 2013). The livestock population of the study district is estimated to be 76336 cattle, 65083 sheep, 84916 goats, 22355 donkeys, 356 camels and 89800 chickens (CSA, 2012).

\section{Study animals}

The study was conducted on 384 apparently healthy slaughtered cattle in Haramaya and Awaday Municipal Abattoirs from November, 2017 to April, 2018. It has been difficult to trace back the origin of animals, since the animals pass a chain of markets. Nevertheless, attempts made in this regard revealed that majority of them were bought from nearby markets. Animals from both local and cross breed cattle were brought to both municipal abattoirs. Even though, the study animals were kept under broad range of management and animals in most of the rural areas were kept to graze pasture on grassland and supplementary feedings of crop residue when pasture in scarce especially during long dry season.

\section{Study design}

A cross sectional study was conducted from November, 2017 to April, 2018 to assess the prevalence of the rumen and reticulum foreign bodies, to identify the types of foreign bodies, and their associated risk factors for the occurrence of the foreign bodies were sex, age, Breed, and body conditions were considered as risk factor for occurrence of foreign bodies.

\section{Sampling method}

A cattle slaughtered during each visit day were selected by systematic random sampling using regular interval to study the prevalence of foreign body and identification of types of foreign bodies in rumen and reticulum in cattle slaughtered at Haramaya and Awaday Municipal Abattoirs of Eastern Ethiopia.

\section{Sample size determination}

The study was carried out by determining the sample size according to Thrusfield (2005), for an infinite population with $95 \%$ confidence level, $5 \%$ desired absolute precision by considering expected prevalence of the rumen and reticulum foreign bodies in cattle in the area. Therefore, the sample size was as follows: 
Where:

$\mathbf{n}=$ required sample size; Pexp = expected prevalence; $\mathbf{d}^{\mathbf{2}}=$ desired absolute precision.

Based on the above formula 384 animals were needed but there was no previous study on the occurrence of rumen and reticulum foreign bodies of cattle slaughtered at haramaya and awaday Municipal Abattoirs. The sample size for this work were determined using $50 \%$ expected prevalence and $5 \%$ absolute precision at $95 \%$ confidence level using the above formula, 384 cattle are intended to be sampled.

\section{Data collections}

Ante mortem examination. Ante mortem examination on individual animals was done for assessment of age, sex, breed, body condition. Sex (female and male), age was categorized into young ( $<5$ years), adult (5-10 years) and old (>10 years), body condition (good, medium and poor). Body condition of cattle was recorded as poor, medium and good based on the appearance of the animal and manual palpation of the spines proses and transverse processes of the lumbar vertebrae described by Nicholson and Butterworth (1986) and breeds was classified as local and cross based on the species of animal brought to abattoir. The age of the animal was also scored according to Mari (1989) based on dentition. Each animal selected for the study was further identified by providing a unique identification number that could be used for both ante-mortem and post-mortem examinations of the animal and each animals mark for the identification by writing a code on its gluteal muscle by using ink.

Postmortem Examination. In the postmortem examination rumen and reticulum were examined. Immediately after slaughtered in the evisceration stage, the stomach was carefully removed from the abdominal cavity and open and explored for the presence of any foreign material by visualization and palpation. Any foreign bodies obtained during inspection are washed by water to removing feed material and identified. When the finding is positive, the location and type of the foreign bodies was recorded otherwise recorded as negative postmortem recorded sheet.

\section{Data management and statistical analysis}

The data collected was entered and scored in Microsoft excel worksheet. Before subjected to statistical analysis, the data were thoroughly screened for errors and properly coded. For analysis SPSS Microsoft software Version 20 was used. Descriptive statistical analysis was used to summarize and present the data collected. The prevalence of rumen and reticulum foreign bodies were calculated as percentage by dividing total number of cattle positive for foreign bodies to the total number of cattle examined. Pearson chi square $\left(x^{2}\right)$ test was employed to assess the existence of association between prevalence of the foreign bodies and potential risk factors considered. For $\left(X^{2}\right)$ test, $p$-value $<0.05$ were considered significant whereas $p$-value $>0.05$ considered non-significant.

\section{RESULT}

A cross sectional study was conducted from November 2017 to March, 2018 at Haramaya and Awaday Municipal Abattoir. From the total of 384 cattle's examined for the presences of any foreign bodies in their rumen and reticulum, $41.7 \%(160 / 384)$ of them were found positive. From 160 positive cases of foreign body, 129 (80.6\%) were occurred in rumen while $16(10 \%)$ in reticulum and $14(8.8 \%)$ in rumen and reticulum. The types of foreign bodies were detected plastics, leathers, clothes, ropes, Stone or Calcified and Metal. From this plastics 75 (46.9\%), cloth $48(30.0 \%)$, rope $34(21.3 \%)$ and leather $30(18.8 \%)$ were more frequently encountered of the positive cases respectively.

\section{Foreign body regarding to breed}

From the total 384 animals 352 local breeds and 32 cross breeds were examined and 136(38.6\%) and 24(75.0\%) of foreign bodies were detected in both breeds respectively. So, the prevalence of rumen and reticulum foreign bodies was higher in cross breed cattle. The statically analysis also showed that there exist highly significant differences among different breed $(p=0.000)$ which is $P<0.05$ in the occurrences of foreign bodies (Table 1$)$.

Table 1 - Breed distribution of rumen and reticulum foreign bodies in cattle at Haramaya and Awaday Municipal Abattoirs.

\begin{tabular}{|c|c|c|c|}
\hline \multirow{2}{*}{ Foreign body } & \multicolumn{2}{|c|}{ Breed } & \multirow{2}{*}{ Tota } \\
\hline & Local & Cross & \\
\hline Plastic & 49 (13.9\%) & $7(21.9 \%)$ & 56 \\
\hline Rope & $15(4.3 \%)$ & - & 15 \\
\hline Cloth & $22(6.2 \%)$ & 1(3.1\%) & 23 \\
\hline Leather & $10(2.8 \%)$ & $4(12.5 \%)$ & 14 \\
\hline Stone or Calcified & $4(1.1 \%)$ & - & 4 \\
\hline Metal & $8(2.3 \%)$ & - & 8 \\
\hline Plastic and rope & $10(2.8 \%)$ & - & 10 \\
\hline Cloth and leather & $7(2.0 \%)$ & $4(12.5 \%)$ & 11 \\
\hline Plastic and cloth & $5(1.4 \%)$ & - & 5 \\
\hline Leather and plastic & - & $4(12.5 \%)$ & 4 \\
\hline Cloth and rope & $5(1.4 \%)$ & $4(12.5 \%)$ & 9 \\
\hline No foreign body & $217(61.6 \%)$ & $8(25.0 \%)$ & 225 \\
\hline Total & 352 & 32 & 384 \\
\hline
\end{tabular}




\section{Foreign bodies relation with age}

Study animals were grouped in to three as young ( $<5$ years), adult (5-10 years) and old ( $>10$ years) From 160 , 194 and 30 animals were examined with age in these age groups, 38(23.8\%), 98(50.5\%) and 24(80.0\%) were found positive, respectively. Foreign bodies were more frequently encountered in old animals than other two groups. The statically analysis also showed that there exist highly significant differences among the three age groups $(p=0.000)$ which is $P<0.05$ in the occurrences of foreign bodies as shows in (Table 2).

\section{Foreign bodies in relation to sex}

From 160 positive animals, $105(50.7 \%)$ and $55(31.1 \%)$ were detected in female and male animals, respectively. Foreign bodies were observed at the maximum of $50.7 \%$ in female cattle compared to male $31.1 \%$. There was statistically strongly significant association $(p=0.00)$ in the frequency of occurrence between male and female (Table 3).

Table 2 - Age distribution of rumen and reticulum foreign bodies in cattle at Haramaya and Awaday Municipal Abattoirs.

\begin{tabular}{|c|c|c|c|c|}
\hline \multirow{2}{*}{ Foreign body } & \multicolumn{3}{|c|}{ Age } & \multirow{2}{*}{ Total } \\
\hline & $\leq 5$ year & 5-10 year & 210years & \\
\hline Plastic & $22(13.8 \%)$ & $32(16.5 \%)$ & $2(6.7 \%)$ & 56 \\
\hline Rope & $6(3.8 \%)$ & $9(4.6 \%)$ & - & 15 \\
\hline Cloth & $3(1.9 \%)$ & $17(8.8 \%)$ & $3(10.0 \%)$ & 23 \\
\hline Leather & - & $10(5.2 \%)$ & $4(13.3 \%)$ & 14 \\
\hline Stone or Calcified & - & $2(1.0 \%)$ & $2(6.7 \%)$ & 4 \\
\hline Metal & $4(2.5 \%)$ & $4(2.1 \%)$ & - & 8 \\
\hline Plastic and rope & $3(1.9 \%)$ & $4(2.1 \%)$ & $3(10.0 \%)$ & 10 \\
\hline Cloth and leather & - & $11(5.7 \%)$ & - & 11 \\
\hline Plastic and cloth & - & $4(2.1 \%)$ & $1(3.3 \%)$ & 5 \\
\hline Leather and plastic & - & $4(2.1 \%)$ & - & 4 \\
\hline Cloth and rope & - & - & $9(30.0 \%)$ & 9 \\
\hline No foreign body & $122(76.2 \%)$ & $97(50.0 \%)$ & $6(20.0 \%)$ & 225 \\
\hline Total & 160 & 194 & 30 & 384 \\
\hline
\end{tabular}

Table 3 - Sex distribution of rumen and reticulum foreign bodies in cattle at Haramaya and Awaday Municipal Abattoirs.

\begin{tabular}{|c|c|c|c|}
\hline \multirow{2}{*}{ Foreign body } & \multicolumn{2}{|c|}{ Sex } & \multirow{2}{*}{ Total } \\
\hline & Female & Female & \\
\hline Plastic & $29(14.0 \%)$ & $27(15.3 \%)$ & 56 \\
\hline Rope & $9(4.3 \%)$ & $6(3.4 \%)$ & 15 \\
\hline Cloth & 22(10.6\%) & $1(0.6 \%)$ & 23 \\
\hline Leather & $11(5.3 \%)$ & $3(1.7 \%)$ & 14 \\
\hline Stone or Calcified & $3(1.4 \%)$ & $1(0.6 \%)$ & 4 \\
\hline Metal & $1(0.5 \%)$ & $7(4.0 \%)$ & 8 \\
\hline Plastic and rope & $7(3.4 \%)$ & $3(1.7 \%)$ & 10 \\
\hline Cloth and leather & $7(3.4 \%)$ & $4(2.3 \%)$ & 11 \\
\hline Plastic and cloth & $3(1.4 \%)$ & $2(1.1 \%)$ & 5 \\
\hline leather and plastic & $4(1.9 \%)$ & - & 4 \\
\hline Cloth and rope & $9(4.3 \%)$ & - & 9 \\
\hline No foreign body & $102(49.3 \%)$ & $123(69.5 \%)$ & 225 \\
\hline Total & 207 & 177 & 384 \\
\hline
\end{tabular}

\section{Foreign body with regard to body condition score}

From total of 384 cattle 24,208 and 152 animals were examined with poor, medium and good body condition, 20 (83.3\%), 130 (62.5\%) and 10 (6.6\%) were positive for foreign body, respectively. The statically analysis also showed that there exist highly significant differences among the three body condition score groups $(p=0.000)$ which is $\mathrm{P}<0.05$ in the occurrences of foreign bodies (Table 4 ).

\section{Foreign bodies with regard to Lodgment sit}

From 160 positive cases of foreign body, 129(80.6\%) were occurred in rumen while $16(10.0 \%)$ in reticulum and $14(8.8 \%)$ in both rumen and reticulum. Prevalence of foreign bodies to lodgment sites was highly statistically significant $(p<0.05)$ (Table 5). 
Table 4 - Prevalence and frequency of rumen and reticulum foreign bodies in cattle slaughtered at Haramaya and Awaday Municipal Abattoirs in association with body condition.

\begin{tabular}{|c|c|c|c|c|}
\hline \multirow{2}{*}{ Foreign body } & \multicolumn{3}{|c|}{ Body Condition Score } & \multirow{2}{*}{ Total } \\
\hline & Poor & Medium & Good & \\
\hline Plastic & $1(4.2 \%)$ & $49(23.6 \%)$ & $6(3.9 \%)$ & 56 \\
\hline Rope & - & $12(5.8 \%)$ & $3(2.0 \%)$ & 15 \\
\hline Cloth & $5(20.8 \%)$ & $18(8.7 \%)$ & - & 23 \\
\hline Leather & $4(16.7 \%)$ & $10(4.8 \%)$ & - & 14 \\
\hline Stone or Calcified & $1(4.2 \%)$ & $3(1.4 \%)$ & - & 4 \\
\hline Metal & $3(12.5 \%)$ & $5(2.4 \%)$ & - & 8 \\
\hline Plastic and rope & $2(8.3 \%)$ & $8(3.8 \%)$ & - & 10 \\
\hline Cloth and leather & $4(16.7 \%)$ & $7(3.4 \%)$ & - & 11 \\
\hline Plastic and cloth & - & $5(2.4 \%)$ & - & 5 \\
\hline Leather and plastic & - & $4(1.9 \%)$ & - & 4 \\
\hline Cloth and rope & - & $9(4.3 \%)$ & - & 9 \\
\hline No foreign body & $4(16.7 \%)$ & $78(37.5 \%)$ & 143(94.1\%) & 225 \\
\hline Total & 24 & 208 & 152 & 384 \\
\hline
\end{tabular}

Table 5 - Frequency of occurrence of rumen and reticulum foreign body in cattle slaughtered at Haramaya and Awaday Municipal Abattoirs.

\begin{tabular}{|c|c|c|c|c|c|}
\hline \multirow[b]{2}{*}{ Foreign body } & \multicolumn{4}{|c|}{ Location site of Foreign Body } & \multirow[b]{2}{*}{ Total } \\
\hline & Reticulum & Rumen & $\begin{array}{l}\text { Rumen and } \\
\text { Reticulum }\end{array}$ & None & \\
\hline Plastic & $3(19.0 \%)$ & $44(34.11 \%)$ & $9(64.3 \%)$ & - & 56 \\
\hline Rope & - & $11(8.53 \%)$ & $4(28.6 \%)$ & _ & 15 \\
\hline Cloth & $1(6.25 \%)$ & $21(16.3 \%)$ & $1(7.14 \%)$ & - & 23 \\
\hline Leather & - & $14(10.9 \%)$ & - & - & 14 \\
\hline Stone or Calcified & $4(25.0 \%)$ & - & - & - & 4 \\
\hline Metal & $8(50.0 \%)$ & - & - & - & 8 \\
\hline Plastic and rope & - & $10(7.8)$ & - & - & 10 \\
\hline Cloth and leather & - & $11(8.53 \%)$ & - & - & 11 \\
\hline Plastic and cloth & _ & $5(3.90 \%)$ & _ & _ & 5 \\
\hline Leather and plastic & _ & $4(3.10 \%)$ & _ & _ & 4 \\
\hline Cloth and rope & - & $9(7.0 \%)$ & _ & - & 9 \\
\hline No foreign body & - & - & - & 225 & 225 \\
\hline Total & 16 & 129 & 14 & 225 & 384 \\
\hline
\end{tabular}

\section{DISCUSSION}

Ingestion of indigestible foreign materials by ruminants is a common problem as reported by Ghurashi et al. (2009). The present study revealed an overall prevalence of $160(41.7 \%)$ of rumen and reticulum foreign bodies in cattle slaughtered at Haramaya and Awaday Municipal abattoirs. This occurrence of foreign bodies is almost similar with report of Sheferaw et al. (2014) who reported $41.8 \%$ in cattle from the Amhara region of Ethiopia and slightly lower than the report from eastern Ethiopia at Haramaya University and Haramaya municipal abattoirs Negash et al. (2015) who reported $43.4 \%$ in cattle and significantly lower than the prevalence (77.41\%) which was reported by Ismail et al. (2007) in adult dairy cattle having indigestible foreign bodies in their fore-stomach, as the result they are suffering from recurrent rumen tympani in Jordan. These differences could be due to the differences in availability of predisposing factors is those area, and the problem of waste management system, poor management of animals and industrialization increased the incidence of foreign bodies between countries. Moreover, the time of the study also could play a role for the differences where in recent times the rate of intensification of animal management is increasing and as a result the probability of animals to be exposed to foreign materials might be declined as the animals are staying in a limited confinement for longer time.

In present study, the higher prevalence $(50.7 \%)$ of foreign bodies was detected in female cattle than male (31.1\%). These results are in agreement with the findings of Vanitha et al. (2010) stating that, the foreign bodies were found more frequently in female cattle than male in their study on $\mathbf{3 0}$ stray cattle having clinical symptoms suggestive of ruminal impaction. Similarly, Zegeye (2011) reported that higher level of occurrence of foreign bodies in female cattle in retrospective study of clinical cases of farm animal in three years period in University of Gondar Veterinary Clinic. Roman and Hiwot (2010) have also reported that higher degree of occurrence of foreign bodies in female ruminants compared to male. This may be due to female animals are more exposed to the environmental 
pollution as they kept for production purpose for longer period of time and there might be increased appetite of female animals due to the nutritional demands during pregnancy and lactation.

The highest frequency of occurrence of rumen and reticulum foreign bodies were detected in animal's $\geq 10$ year $(80.0 \%)$ followed by $5-10$ years $(50.5 \%)$ and $\leq 5$ years $(23.8 \%)$ age group of animals. Highest prevalence $(80.0 \%)$ of foreign bodies was detected in cattle greater than 10 year than other age group. This finding is in agreement with Desiye and Mersha (2012) who recover (81.25\%) of foreign bodies in cattle greater than 10 year age. Rahel (2011) also reported (17.85\%) of the animals had higher frequency of foreign bodies in rumen and reticulum in the old age. The present Prevalence is relatively high since it may be that ingestion of foreign bodies is associated with shortage of forage during the long dry season, owners were not supply supplementary feed and increased demand of feed, and pollution of grazing land with indigestible foreign bodies.

In this finding, the prevalence was higher in the cross breed cattle (75.0\%) compare to local breeds (38.6\%). This findings are agree with the work of Desiye and Mersha (2012) who found $70 \%$ in cross breed and $10.77 \%$ in local breed and Rahel (2011) who reported forestomach foreign bodies with the high prevalence of $58.82 \%$ in crossbreeds. Sileshi et al. (2013) reported that cross breed animals are more exposed for indigestible foreign bodies than local breeds. The higher prevalence in cross breed might be associated with their higher productivity which requires high demand of nutrition that enforces cattle to indiscriminately feeding and hence increased exposure to foreign bodies.

This study also identified the highest prevalence of rumen and reticulum foreign bodies were detected in animals with poor body condition (83.3\%) followed by medium (62.5\%) and good body condition $(6.6 \%)$ score animals. This finding agree with the work of Desiye and Mersha (2012) who recovered foreign body at higher prevalence from the rumen and reticulum of poor body conditioned animal $(72.72 \%)$ than medium (35.95\%) and good $(7.33 \%)$ body condition. Poor body condition by itself might be due to the contribution of the foreign body that is the animal loss weight after it has been exposed or it might be due to the interference of foreign body with the absorption of volatile fatty acid (VFA) and thus causes reduced weight gain reported by Rahel (2011).

Metallic foreign bodies were most frequently recovered from reticulum. This finding agrees with the report of (Sileshi et al., 2012) who recovered metallic foreign bodies at highest prevalence from reticulum. In addition, Desiye and Mersha (2012) reported the highest prevalence $(87.5 \%)$ of metallic foreign bodies from reticulum. The reason might be due to retention of these foreign bodies by the honey comb structure of the reticular mucosa and their heavy weight give chance to be attracted to the lumen of the reticulum due to gravitational attraction force of these heavy foreign bodies to the ventral part of the fore-stomach.

The types of foreign bodies detected in this study were plastic, cloth, leather, rope, metal (wire) and stone or calcified. Berrie et al. (2015) also found the same thing. This study indicated that most foreign bodies occurred in the rumen $(80.6 \%)$ than reticulum $(10 \%)$. This may be due to the fact that many ingested feed goes to the rumen. The results of this study further indicate that Plastic was the most commonly encountered (45.6\%) foreign material in all study animals, followed by cloth (30.0 \%) and rope (21.3\%). This finding is in general agreement with various reports from different areas of Ethiopia (Abebe and Nuru 2011; Roman and Hiwot 2010; Sheferaw et al., 2014; Tesfaye et al., 2012). This is due to these materials used for storing wastes, shopping bags and packing food items and disposed everywhere after using, hence they were eaten by the free grazing animal.

\section{CONCLUSTION AND RECOMMENDATIONS}

The current finding is used to assess the prevalence of rumen and reticulum foreign bodies, to identify the type of foreign bodies and to identify the magnitude and occurrence of fore stomach foreign bodies done in Haramaya and Awaday municipal abattoirs. Sex, breed, age, and body condition score were considered risk factors for the occurrence of foreign bodies. And this study revealed that rumen and reticulum foreign bodies have great economic significance associated with reduced production and productivity of animals suffering from them. The overall prevalence of foreign bodies was $160(41.7 \%)$. Similarly, Plastic was found the most common foreign bodies found preferably in Rumen (34.11\%). On the other hand, Female (14.0\%) local breeds (13.9\%), aged 5-10 years (16.5\%) with medium body condition (23.6\%) were mostly affected. Degree of association was highly statistically significant for the occurrence of foreign body in cattle. Both female and cross breed cattle are the most affected groups compared to that of male and local breed cattle respectively. According to body condition score of cattle, poor body conditions were more affected groups than cattle which have medium and good body conditions. Most of the nonmetallic foreign bodies lodged in rumen while metallic foreign bodies lodged in reticulum.

Awareness for owners should be implemented to avoid the risk of foreign body ingestion such as prevent nutritional deficiencies and not allowing animals in polluted grazing land. Appropriate solid waste disposal system should be implemented. Enforcement of recycling of plastic bags and other environmental pollutants so that threat to environment and life can be reduced. The finding of this study could help environmental activists, veterinarians, and livestock owners to recognize the impact of foreign bodies on cattle's health and productivity in this area.

\section{DECLARATION}

\section{Authors' contribution}

The two authors reviewed the paper and contributed in developing the content.

\section{Availability of data}

The data can be availed to the journal upon request. 


\section{Consent to publish}

Not applicable

\section{Conflict of interest}

The authors declare they have no competing of interests.

\section{Acknowledgement}

The authors would wish to acknowledge Eco Fuels Kenya LTD (EFK) for their support through the whole process of developing this publication.

\section{REFERENCES}

Abebe F and Nuru M (2011). Prevalence of indigestible foreign body in small ruminants slaughtered at Luna export Abattoir, East Shoa, Ethiopian. Journal of Animal and Veterinary Science, 10(12): 1598-1602. DOI: https://dx.doi.org/10.3923/javaa.2011.1598.1602 I Google Scholar

Abu-Seida AM and Al-Abbadi OS (2014). Recurrent rumen Tympany caused by trichobezoars in buffaloes (Bubalus bubalis), a series report. Thai Journal of Veterinary Medicine, 44:147-151. https://he01.tci-thaijo.org/index.php/tjvm/article/view/17325/15577

Abu-Seida AM and Al-Abbadi OS, (2016). Recent advances in the management of foreign body syndrome in cattle and buffaloes: A Review. Pakistan Veterinary Journal, 36(4): 385-393. http://www.pvj.com.pk/pdf-files/36 4/385-393.pdf I Google Scholar

Anwar K, Khan I, Aslam A, Mujtaba M, Din A, and Amin Y (2013). Prevalence of indigestible rumen and reticulum foreign bodies in Achai cattle at different regions of KhyberPakhtunkhwa. ARPN Journal of Agricultural and Biological Science, 8(8): 580-586. Direct Link I Google Scholar

Atawalna J, Kotoku V, Ewura S (2015). Prevalence of indigestible foreign materials in small ruminants slaughtered at the kumasi abattoir of Ghana. International Journal of Livestock Resource, 5: 1-7. Google Scholar, CAB Direct

Bakos Z and Vörös K (2011). Intraoperative echocardiography and surgical treatment of traumatic pericarditis in a pregnant cow. Acta Veterinary Hungarica, 59(2):175-179. DOI: https://doi.org/10.1556/avet.2011.001

Bassa K and Tesfaye W (2017). Study on Rumen and Reticulium foreign bodies in cattle slauthered at WolaitaSodo municipal Abattoir, Ethoipia. International Journal of Advanced Multidisciplinary Research, 4(1): 11-19. DOI: https://doi.org/10.22192/ijamr

Bayne JE, and Edmondson, M.A (2020). Diseases of the gastrointestinal system. Sheep, Goat, and Cervid Medicine, 2021: 63-96. Doi: https://doi.org/10.1016/B978-0-323-62463-3.00014-1

Berrie KE, Berihun TM and Bewuket A (2015). Study on rumen and reticulum Foreign body in slaughtered cattle at gonder Elfora Abbattoir Ethiopia University of Addis Ababa, College of veterinary medicine and agriculture, Debrezeit, Ethiopia. World Journal of Biology and Medical Science, 2 (4):133-150. http://www.sasjournals.com/Oct_Dec_15/16.\%20STUDY\%200N\%20133-150.pdf

Bhaskara MVR and Sasikala P (2012). A Review on foreign bodies with special reference to plastic pollution threat to live stock and environment in tirupati rural areas. International Journal of Scientific and Research Publications, 2(12):1-6. http://www.ijsrp.org/research-paper1212/ijsrp-p1238.pdf

Braun U, Warislohner S, and Torgerson P. (2018).Clinical and laboratory findings in 503 cattle with traumatic reticuloperitonitis. BMC Veterinary Research, 14: 66. https://doi.org/10.1186/s12917-018-1394-3.

Bwatota SF, Makungu M, and Nonga HE (2018). Occurrences of Indigestible Foreign Bodies in Cattle slaughtered at morogoro municipal slaughterhouse, Tanzania. Journal of Veterinary Medicine, 2018:4818203. DOI: https://dx.doi.org/10.1155/2018/4818203.

Central Statistical Agency (CSA) (2012). Federal Democratic Republic of Ethiopia. Agricultural sample survey Report on livestock on livestock characteristics, Volume 2. Statistical Bulletin 532, Addis Ababa. Google Scholar

Central Statistical Agency (CSA), (2013). Federal Democratic Republic of Ethiopia. Agricultural Sample Survey Report on Livestock and livestock characteristics. Volume 2, (Private peasant holdings/ Addis Ababa).

Central statistics authority (CSA), (2013). Populations projection of Ethiopia for all region at district level from 2014-2017.CSA, Addis Ababa, Ethiopia.

Desiye T and Mersha C (2012). Study on Rumen and Reticulum Foreign Bodies in Cattle Slaughtered at Jimma Municipal Abattoir, South West $\begin{array}{lllll}\text { Ethiopia. American-Eurasian } & \text { Journal } & \text { of } & \text { Scientific } & \text { Research, }\end{array}$ https://scholar.google.com/scholar?cluster $=5112769433611780926 \& \mathrm{hl}=\mathrm{en} \& a \mathrm{~s}$ sdt=0,5

Fasil N (2016). Assessment of Sheep and Goat Foreign Bodies in Rumen and Reticulum in the Jigjiga Municipal Abattoir. Advances in Dairy Research, 4: 157. DOI: https://dx.doi.org/10.4172/2329-888X.1000157.

Ghurashi, M., Seri, H., Bakheit, H. and Ashwag, M. (2009). Effect of surgical removal of foreign body from goat's rumen with special reference to the prevalence of foreign body in goats in Southern Darfur. Australian Journal of Basic and Applied Sciences, 3(2): 664-668. Google Scholar, PDF

Gupta SK and Singla LD (2013). Diagnostic trends in parasitic diseases of animals, in veterinary diagnostics current trends, gupta RP, Garg SR, Nehra V, Lather D (Eds). Satish serial publishing house. Delhi, p, 81-112. Google Scholar

Kahn CM and Line S (2010). The Merck veterinary manual, 10 ${ }^{\text {th }}$ ed. Merck and Co., Whitehouse Station, NJ. Google Scholar

Mekonnen A and Uttama R (2014). Assessment of potable water supply in Awaday town in Oromiya region, Ethiopia. Haramaya University, International Journal of Social Science, 19(1): 65- 72. https://www.tijoss.com/19\%20volume/7utam.pdf

Mersha C and Desiye T (2012). Clinico-pathological findings of metallic and non-metallic foreign bodies in dairy cattle.Areview. Academic Journa of Animal Diseases, 1(3): 13-20. DOI: https://doi.org/10.5829/idosi.ajad.2012.1.3.7524

Negash S, Sibhat B. and Sheferaw D (2015). A postmortem study on indigestible foreign bodies in the rumen and reticulum of ruminants eastern Ethiopia. Onderstepoort Journal of Veterinary Research, 82(1): 01-05. doi: https://doi.org/10.4102/ojvr.v82i1.881

Nicholson MJ and Butterworth MH (1986). A guide to condition scoring of zebu cattle. International Livestock Center for Africa, Addis Ababa, Ethiopia. pp, 1- 29. Google Scholar

Priyanka M, Dey S (2018). Ruminal impaction due to plastic materials - An increasing threat to ruminants and its impact on human health in developing countries. Veterinary World, 11(9): 1307-1315. DOI: https://doi.org/10.14202/vetworld.2018.1307-1315

Rahel M (2011). Study on fore stomach foreign body in cattle Slaughtered Hawasa Municipal Abattoir, Ethiopia, DVM thesis Gondar University, Faculty of Veterinary Medicine, Gondar, Ethiopia, p, 3-9. Google Scholar 
Ramaswamy V and Sharama H (2011). Plastic bags threat to environmental and cattle health, A retrospective study from Gondar city of Ethiopia. The IIOAB Journal; Special Issue on Environmental Management for Sustainable Development, 2: 7-12. Google Scholar I PDF

Ramin AG, Hashemi A M, Asri-Rezaie S, Batebi E, Tamadona A. and Ramin S (2011). Prediction of traumatic pericarditis in cows using some serum biochemical and enzyme parameters. Acta Veterinary, 61: 383-390. DOI: https://dx.doi.org/10.2298/AVB1104383R

Reddy MV and Sasikala P. (2012). A review on foreign bodies with special reference to plastic pollution threat to livestock and environment in Tirupati rural areas. International Journal of Scientific and Research Publications, 2: 1-8. http://www.ijsrp.org/research-paper-1212/ijsrpp1238.pdf

Reuters (2019). Govt shelves plan on countrywide ban on single-use plastic products: Report . Accessed on 24th May, 2020. Available at: https://www.dnaindia.com/india/report-govt-shelves-plan-on-countrywide-ban-on-single-use-plastic-products-report-2793974.

Roman T and Hiwot T. (2010). Occurrence of rumen fibrinogen for the diagnosis of traumatic foreign bodies in Sheep and Goat slaughtered at Addis Ababa Municipal Abattoir. Ethiopia Veterinary Journal, 14: 91-100. https://www.ajol.info/index.php/evj/article/view/63872

Schipper IA (2000). Lecture outline of preventive Veterinary Medicine. $6^{\text {th }}$ ed. Surgeet Publishing, p, $166-167$.

Serem EK, Abuom TO, Peter SG, Gakuya DW, Kirui GK and Mbuthia PG (2019). Microcardia associated with Traumatic Reticulo Pericarditis (TRP) in an adult female ayrshire cow: a case report. International Journal of Veterinary Science, 8(2): 73-78. http://www.ijvets.com/pdffiles/Volume-8-no-2-2019/73-78.pdf

Sheferaw D, Gebru F and Asrat M (2014). Ingestion of indigestible foreign materials by free grazing ruminants in Amhara Region, Ethiopia. Tropical Journal of Animal Healthy Production, 46: 247-250. DOI: https://dx.doi.org/10.1007/s11250-013-0484-2

Sileshi N, Ramaswamy V, Chandrashekhar U and Raja N (2013). Studies on foreign body ingestion and their related Complications in ruminants associated with inappropriate Solid Waste Disposal in Gondar Town, North West Ethiopia. International Journal of Animal and Veterinary Advances, 5(2): 67-74. https://maxwellsci.com/print/ijava/v5-67-74.pdf

Smith B (2009). Large Animal Internal Medicine. $4^{\text {th }}$ ed.: USA. Mosby Elsevier, p 849-850

Tesfaye D, Yismaw S and Demissie T (2012). Ruminal and reticular foreign bodies in small ruminants slaughtered at Jimma Municipal Abattoir, Southwestern Ethiopia American-Eurasian Journal of Scientific Research, 7 (4): 160-167. DOI: https://dx.doi.org/10.5829/idosi.aejsr.2012.7.4.65140

Thrusfield M. (2005). Veterinary Epidemiology. $3^{\text {rd }}$ ed. Burgh: U.K. Blackwell Science UK, p, 233. Google Scholar

Vanitha V, Nambi AP, Gowri B and Kavitha S (2010). Rumen impaction in cattle with indigestible foreign bodies in Chennai. Tamilnadu Journal of Veterinary and Animal Science, 6(3): 138-140. https://www.researchgate.net/publication/316686003

Zegeye B (2011). Retrospective Study on Disease of Farm Animals. Senior Paper, Presented to Gondar University Veterinary Clinic, Faculty of Veterinary Medicine, University of Gondar, Ethiopia, p, 21. 